\title{
GTPases: prerequisite molecular target in virulence and survival of Mycobacterium tuberculosis
}

Keyword: M. Tuberculosis, gtpases, g protein, gpcrs, ef-tu lepa, ffh, ftsy, obg, era, enga

\section{Short summary of gtpases}

Proteins binding to guanine nucleotide such as guanosine diphosphate (GDP) and guanosine triphosphate (GTP) are termed as GTP binding protein or G protein. G proteins are enormous in both eukaryotes and prokaryotes and are known to play vital role in various fundamental process of life as cell proliferation, signal transduction, protein translation, etc by regulating the activity of GTPase. ${ }^{1} \mathrm{G}$ proteins are hetrotrimeric structurally and are composed of three subunits $G \alpha, G \beta$ and $G \gamma$; with $G \alpha$ carrying active site for binding of nucleotides. G-proteins coupled receptors (GPCRs) are group of seven transmembrane proteins that on binding to relevant ligand brings about conformational change in structure of $\mathrm{G}$ protein that assists binding of GTP/GDP with G proteins. ${ }^{2}$ In eukaryotes GTPases are basically involved in various translational steps, while prokaryotic GTPase are eminent regulators of ribosomal functions and are distributed in daughter cell during cell division. ${ }^{3}$

GTPase constitutes of a protein super family having highly conserved molecular switches involved in several cell function. GTPase undergoes three conformational changes, GDP on binding with the $\alpha$-subunit keep the protein in inactive form as it remain bound with other two $\beta$ and $\gamma$ subunits. On binding of GTP with $\alpha$ subunit, brings about conformational change in the protein structure by dissociating the $\alpha$-subunit from $\beta$ and $\gamma$ subunits; thus in turn allowing the protein to bind with the target molecule or ligand. Further this GTP on action by GTPase gets hydrolyzed form GDP thus resulting in protein's inactivation. ${ }^{4}$

There are 13 universally conserved core GTPases known in bacteria till date. According to the reports it has been stated that these core GTPases are either involved in ribosomal function or signal transmission. ${ }^{5}$ These core GTPases protein are elongation factor $\mathrm{G}(\mathrm{Ef}-\mathrm{G})$, elongation factor $\mathrm{Tu}(\mathrm{Ef}-\mathrm{Tu})$, initiation factor 2(If-2),YihA, LepA, Thd F/ Trm E, Ffh, FtsY, Obg, Era, EngA, Der and Ych F that are found in prokaryotes and are involved basically in ribosomal functions. ${ }^{6}$ In many bacteria several GTPases among these are very important for cell viability itself. In M. Tuberculosis Ef-Tu, LepA, Ffh, FtsY, Obg, Era and EngA are few GTPase protein found that play significant role in its virulence and also aids in the survival of bacterium under stress condition. ${ }^{7,8}$ M. Tuberculosis Ef-Tu (Mtb Ef$\mathrm{Tu}$ ) has not yet been characterized although it has been found to remain associated with the cell wall ${ }^{7}$ and induce under anaerobic condition with high iron containing media. ${ }^{7,9}$ Also it has been reported to bind with human plasminogen. ${ }^{7,10}$ Phosphorylation mediated Mtb Ef-Tu play cogent role in dormancy of $M$. tuberculosis by down-regulating the binding with GTP thus, adversely affecting protein synthesis.?

LepA gene codes for highly conserved protein in bacteria and acts as an essential elongation factor. ${ }^{1}$ This protein has been reported to play crucial role in survival of Helicobacter pyroli in acidic condition by signalling the environmental change outside the bacterium. ${ }^{8}$ In
Volume I Issue I - 2016

\author{
Laxman S Meena, Siuli Shaw \\ CSIR-Institute of Genomics and Integrative Biology, India
}

Correspondence: Laxman S Meena, CSIR-Institute of Genomics and Integrative Biology, India, Mall Road, Delhi-I I0007, Tel 0I I-27666I 56, Fax 0I I-2766747, Email meena@igib.res.in

Received: October 27, 2016 | Published: November 30, 2016

Mycobacterium avium (M. Avium) mutated gene MAV_1778 which functions as LepA GTP binding protein have shown enhanced growth rate in neutral to acidic $\mathrm{pH}^{11}$ which depicts the idea that presence of LepA in M. Tuberculosis may also enable its survival inside host even in adverse condition.

$\mathrm{Ffh}$ is homolog of $54 \mathrm{kDa}$ eukaryotic protein that binds to single sequence of pre-protein (SRP) which aids in recognition of single sequence of polypeptide emerging from ribosome. ${ }^{12} \mathrm{Ffh}$ protein can be categorized into three domains; $M$ domain which is methionine rich, interacts with single peptide; $G$ domain involving in GTPase activity that aids in docking action and subsequently releases peptide at translocon; finally the highly conserved $\mathrm{N}$ domain plays important role in control of the GTP occupancy of G domain. ${ }^{13}$ FtsY in bacteria is homolog of $\mathrm{Ffh}$ gene having similar $\mathrm{G}$ and $\mathrm{N}$ domain region ${ }^{13}$ and have complimentary role in membrane bound signal recognition.

Obg is monomeric $\mathrm{G}$ protein found in case of both eukaryotic as well as prokaryotic organism. Gene encoding Obg was firstly identified in Bacillus subtilis and was reported to implement sporulation, mycelium development, stress response and chromosome partitioning and its orthologues has been reported in case of Streptomyces griseus, Streptomyces coelicolor, Caulobacter crescentus, Echerichia coli and Vibrio harveyi. ${ }^{8,14}$ In case of M. tuberculosis gene Rv2240c encodes for Obg protein which has elevated expression and resulted in 5 fold more division in $\log$ as well as in stationary phase thus being hypothesised it significant role in bacterial membrane assembly. Also, Obg has been found associated with ribosomal subunit (30S, 50S) and simultaneously binds with stress protein UsfX. ${ }^{14}$ Era protein derives its name from E. Coli is a $\mathrm{G}$ protein which is also found in Salmonella typhimurium and Streptococcus mutans and acts as an important growth factor in these organisms. ${ }^{8,15}$ In M. tuberculosis replacement of position in alanine residue has shown loss in GTPase activity thus indicating its importance in bacteria. ${ }^{8}$ Eng A consists of two GTP binding domain and was firstly discovered in Neisseria gonorrhoeae (N. Gonorrhoeae) and in study of S. Typhimurium this protein was found to interact with the smaller ribosomal subunit $30 \mathrm{~S}$ in S7 and S9 which focus the concept of its involvement in ribosomal assembly. In M. Tuberculosis Eng A protein has shown intrinsic GTP binding and hydrolysing property by its molecular characterization is yet to be done to reveal its exact role. ${ }^{16}$ 
In conclusion, we would like to summarize that Guanine nucleotide are active signalling molecules targeting GTP by hydrolyzing it and regulates intracellular level of GDP and GTP in many prokaryotes. Several core GTPases are highly conserved in infectious bacterium like M. Tuberculosis, thus could be characterized on molecular level, which in turn would aid in understanding the key mechanism of mode of action in causing infection and survival of organism inside host in stressed condition. Further more detailed study may be required to understand the physiological functions of GTPases family proteins to develop anti-TB drugs.

\section{Acknowledgements}

We thank Dr. Rajesh S. Gokhale for making this work possible. The authors acknowledge financial support from GAP0092 and OLP1121 of the Department of Science and Technology and Council of Scientific \& Industrial Research.

\section{Conflict of interest}

Author declares that there is no conflict of interest.

\section{References}

1. Reddington K, Grady JO, Raj SD, et al. A Novel Multiplex Real-Time PCR for the Identification of Mycobacteria Associated with Zoonotic Tuberculosis. PLoS One. 2011;6(8):e23481.

2. Shalaeva DN, Galperin MY, Mulkidjanian AY. Eukaryotic G proteincoupled receptors as descendants of prokaryotic sodium-translocating rhodopsins. Biol Direct. 2015;10:63.

3. Meena R, Meena LS. Guanosine triphosphatases as novel therapeutic targets in tuberculosis. Int J Infect Dis Volume. 2010;14(8):e682-7.

4. http://www.biology-pages.info/G/G_Proteins.html

5. Caldon CE, Yoong P, March PE. Evolution of a molecular switch: universal bacterial GTPases regulate ribosome function. Mol Microbiol. 2001;41(2):289-297.

6. Verstraeten N, Fauvart M, Versées W, et al. The Universally Conserved Prokaryotic GTPases. Microbiol Mol Biol Rev. 2011;75(3):507-542.
7. Sajid A, Arora G, Gupta M, et al. Interaction of Mycobacterium tuberculosis Elongation Factor Tu with GTP Is Regulated by Phosphorylation. J Bacteriol. 2011;193(19):5347-5358.

8. Meena LS, Chopra P, Bedwal RS, et al. Cloning and characterization of GTP-binding proteins of Mycobacterium tuberculosis $\mathrm{H}_{37} \mathrm{Rv}$. Enzyme and Microbial Technology. 2008;42(2):138-144.

9. Wong DK, Lee BY, Horwitz MA, et al. Identification of Fur, aconitase, and other proteins expressed by Mycobacterium tuberculosis under conditions of low and high concentrations of iron by combined twodimensional gel electrophoresis and mass spectrometry. Infect Immun. 1999;67(1):327-336.

10. Xolalpa W, Vallecillo AJ, Lara M, et al. Identification of novel bacterial plasminogen-binding proteins in the human pathogen Mycobacterium tuberculosis. Proteomics. 2007;7(8):3332-3341.

11. Khattak FA, Kumar A, Kama E, et al. Illegitimate recombination: An efficient method for random mutagenesis in Mycobacterium avium subsp. Hominissuis. BMC Microbiol. 2012;12:204.

12. Zopf D, Bernstein HD, Johnson AE, et al. The methionine-rich domain of the $54 \mathrm{kDa}$ protein subunit of the signal recognition particle contains an RNA binding site and can be crosslinked to a signal sequence. $E M B O$ J. 1990;9(13):4511-4517.

13. Palaniyandi K, Veerasamy M, Narayanan S. Characterization of Ffh of Mycobacterium tuberculosis and its interaction with 4.5S RNA. Microbiological Research. 2012;167(9):520-525.

14. Sasindran SJ, Saikolappan S, Scofield VL, et al. Biochemical and physiological characterization of the GTP-binding protein Obg of Mycobacterium tuberculosis. BMC Microbiol; 2011;11:43

15. Gollop N, March PE. A GTP-binding protein (Era) has an essential role in growth rate and cell cycle control in Escherichia coli. J Bacteriol. 1991;173(7):2265-2270.

16. Meena LS, Rajini. Cloning and characterization of engA, a GTPbinding protein from Mycobacterium tuberculosis $\mathrm{H}_{37} R v$. Biologicals. 2011;39(2):94-99. 